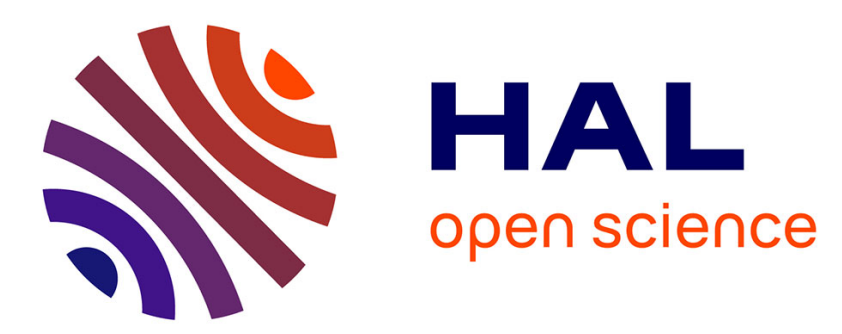

\title{
Modern flexible ureteroscopy in Cohen cross-trigonal ureteral reimplantations
}

Esteban Emiliani, Michele Talso, Marie Audouin, Olivier Traxer

\section{To cite this version:}

Esteban Emiliani, Michele Talso, Marie Audouin, Olivier Traxer. Modern flexible ureteroscopy in Cohen cross-trigonal ureteral reimplantations. Journal of Pediatric Urology, 2017, 10.1016/j.jpurol.2017.03.009 . hal-01501345

\section{HAL Id: hal-01501345 \\ https://hal.sorbonne-universite.fr/hal-01501345}

Submitted on 4 Apr 2017

HAL is a multi-disciplinary open access archive for the deposit and dissemination of scientific research documents, whether they are published or not. The documents may come from teaching and research institutions in France or abroad, or from public or private research centers.
L'archive ouverte pluridisciplinaire HAL, est destinée au dépôt et à la diffusion de documents scientifiques de niveau recherche, publiés ou non, émanant des établissements d'enseignement et de recherche français ou étrangers, des laboratoires publics ou privés. 


\title{
ACCEPTED MANUSCRIPT
}

\section{Modern flexible ureteroscopy in Cohen Cross-Trigonal ureteral reimplantations.}

\author{
Emiliani $\mathrm{E}^{\mathrm{a}, \mathrm{b}, \mathrm{c}}$. Talso $\mathrm{M}^{\mathrm{a}}$. Audouin $\mathrm{M}^{\mathrm{a}}$. \\ Traxer $\mathrm{O}^{\mathrm{a}, \mathrm{c}}$
}

a: Hopital Tenon, department of urology . université pierre et marie curie Paris IV. Paris, France b: Fundacion Puigvert, department of urology. Universitat Autonoma de Barcelona, Barcelona, Spain.

c: GRC lithiase (Grouped Recherche Clinique) Université Paris VI, Pierre et Marie Curie, Paris, France

Authors:

Esteban Emiliani

-Hopital Tenon, department of urology . université pierre et marie curie Paris IV. Paris, France -Fundacion Puigvert, department of urology. Universitat Autonoma de Barcelona, Barcelona, Spain.

- GRC lithiase (Grouped Recherche Clinique) Université Paris VI, Pierre et Marie Curie, Paris, France emiliani@gmail.com

Michele Talso

Hopital Tenon, department of urology . université pierre et marie curie Paris IV. Paris, France

Marie Audouin

Hopital Tenon, department of urology . université pierre et marie curie Paris IV. Paris, France

Olivier Traxer

-Hopital Tenon, department of urology . université pierre et marie curie Paris IV. Paris, France

- GRC lithiase (Grouped Recherche Clinique) Université Paris VI, Pierre et Marie Curie, Paris,

France

olivier.traxer@aphp.fr

\section{Correspondent author:}

Olivier Traxer

Tenon Hospital.

Pierre and Marie Curie University

Department of Urology

4 Rue de la Chine

75020 Paris, France

olivier.traxer@aphp.fr

Acknowledgments: Dr. Esteban Emiliani is supported by the EUSP

scholarship from the European Association of Urology.

Conflict of interest: None

Funding: None 


\title{
HOW I DO IT
}

\section{Modern flexible ureteroscopy in Cohen cross-trigonal ureteral reimplantations}

Esteban Emiliani ${ }^{a, b, c}$, Michele Talso ${ }^{a}$, Marie Audouin ${ }^{a}$, Oliver Traxer ${ }^{a, c, *}$

a Department of Urology, Hopital Tenon, Université Pierre et Marie Curie Paris IV, Paris, France

${ }^{b}$ Department of Urology, Fundacion Puigvert, Universitat Autonoma de Barcelona, Barcelona, Spain

${ }^{c}$ GRC lithiase (Grouped Recherche Clinique) Université Paris VI, Pierre et Marie Curie, Paris, France

* Corresponding author. Tenon Hospital, Pierre and Marie Curie University, Department of Urology, 4 Rue de la Chine, 75020 Paris, France.

E-mail address: olivier.traxer@aphp.fr (O. Traxer).

\begin{abstract}
We describe a feasible flexible ureteroscopy (fURS) technique with the latest instruments to and to discuss their advantages. Three patients underwent a fURS for stone treatment. A 7F angled orifice catheter and a hydrophilic angled tip stiff wire is used to guide the wire in the proper ureteral direction sighting the ureter allowing the use of a 10/12 ureteral access sheath. A single use ureteroscope was used. All of them had successful ureteral access and laser lithotripsy being stone free endoscopically. No complications reported. The modern fURS technique was found feasible and safe in patients with crosstrigonal ureteroneocystostomy.
\end{abstract}

\section{KEYWORDS}


Ureteroscopy; Flexible ureteroscopy; Laser; Urolithiasis; Cohen reimplantation

\section{Introduction}

Cohen cross-trigonal ureteroneocystostomy $(\mathrm{Cl})$ is a common anti-reflux technique that creates a submucosal tunnel while advancing the ureteral orifice to the opposite side of the trigone [1]. Patients undergoing Cohen cross-trigonal ureteroneocystostomy have an increased risk of developing urolithiasis; the mean interval until presentation being 7 years following the procedure [2].

Flexible ureteroscopy (fURS) is a challenging procedure in abnormal ureteral anatomies and precise surgical strategies must be performed to achieve successful ureteral access without harming the ureteral orifice or the instruments. The aim of this study is to describe a feasible fURS technique with the latest instruments and to identify its advantages.

\section{Technique}

Under general anesthesia, the patient is positioned in a Galdakao-modified supine position (Fig. 1). Cystoscopy is performed to identify the ureteral orifices. A $7 F$ angled orifice catheter and a 0.035 -inch hydrophilic angled tip stiff wire (Fig. 2) are used to guide the wire in the proper ureteral direction. After achieving the entry, passing a large amount of wire or the catheter reorients the kinked ureter to a straight axis (Fig. 2). A 10/12 ureteral access sheath (UAS) is placed, retaining the safety wire (Fig. 3). The current standard fURS technique is performed. A double $\mathrm{J}$ stent is left at the end of the procedure (Fig. 4).

\section{Results}


From January 2016 to July 2016, four fURS were carried out using crosstrigonal ureteroneocystostomy in three male patients aged 16,28 , and 41 years (one bilaterally). All of the patients had successful ureteral access and laser lithotripsy and were found to be stone free endoscopically. The mean operative time was 90 minutes. Patients were discharged at day 1 . The stent was removed one week later. No intra- or postoperative complications were reported.

\section{Discussion}

A key aspect of this technique is positioning the patient for combined endoscopic surgery, if retrograde access is not achieved [3]. An antegrade wire to recognize the orifice in the bladder may be sufficient.

Although the site of the reimplantation is well delineated, the orifices are not well defined. Ureteral peristalsis is seen and can be taken as a good sign of the orifice site.

For access, a 4F curved tip angiographic catheter and a Cobra-head catheter have been described [4,5]. We recommend using an angled tip hydrophilic wire to ensure easy passage; non-traumatic access assists in avoiding bleeding. The wire must be stiff as it can reorient the kinked ureter to a straight axis by itself. The rigidity of a 7F catheter may allow easier straightening of the ureter than is possible with a $4 \mathrm{~F}$ catheter. Furthermore, it is cost-effective. Having a straight ureter allows easier insertion of a small 10/12 UAS that offers advantages such as the potential for multiple re-entries and maintenance of low intrarenal pressures. From this point onward, standard fURS can be performed [6]. It is advised that the smallest instruments possible 
should be used; if required, a small $7.5 \mathrm{~F}$ scope can be inserted directly through the guidewire without the use of UAS.

Finally, if the UAS is not used and the scope must be placed in an extremely kinked ureter though the wire, reusable scopes are now available to avoid damage and costly repairs associated with forcing standard scopes. If access is difficult, the patient can be pre-stented and surgery delayed.

\section{Conclusion}

The modern fURS technique was found to be feasible and safe in patients with Cohen cross-trigonal ureteroneocystostomy .

\section{Conflict of interest}

None.

\section{Funding}

Esteban Emiliani is supported by an EUSP scholarship from the European Association of Urology.

\section{References}

[1] Cohen SJ. The Cohen reimplantation technique. Birth Defects Orig Artic Ser 1977;13:391-5.

[2] Krambeck AE, Gettman MT, BaniHani AH, Husmann DA, Kramer SA, Segura JW. Management of nephrolithiasis after Cohen cross-trigonal and Glenn-Anderson advancement ureteroneocystostomy. J Urol 2007;177:174-8. [3] Scoffone CM, Cracco CM, Cossu M, Grande S, Poggio M, Scarpa RM. Endoscopic combined intrarenal surgery in Galdakao-modified supine Valdivia 
position: A new standard for percutaneous nephrolithotomy? Eur Urol 2008;54:1393-403.

[4] Argueso LR, Kelalis PP, Patterson DE. Strategies for ureteral catheterization after antireflux surgery by the Cohen technique of transverse advancement. J Urol 1991;146:1583-4.

[5] Wallis MC, Brown DH, Jayanthi VR, Koff SA. A novel technique for ureteral catheterization and/or retrograde ureteroscopy after cross-trigonal ureteral reimplantation. J Urol 2003;170:1664-6

[6] Giusti G, Proietti S, Villa L, Cloutier J, Rosso M, Gadda GM, et al. Current standard technique for modern flexible ureteroscopy: Tips and tricks. Eur Urol 2016;70:188-94.

Figure 1 Galdakao-modified supine position for endoscopic combined surgery. Figure 2 (A) 7F angled tip catheter (Coloplast, Rosny-sous-Bois, France) and a 0.035-inch angled tip hydrophilic Terumo stiff wire (Terumo, Tokyo, Japan). (B) Endoscopic view of the inverted orifice disposition and access (superior orifice right kidney orifice with wire, inferior left kidney orifice with double J).(C) Crosstrigonal ureteral kinking with wire in place. (D) Ureteral reorientation in a straight axis.

Figure 3 10/12 Re-trace ureteral access sheath (Coloplast, Rosny-sous-Bois, France) in place in the straight ureter with a safety guidewire. A disposable ureteroscope was used.

Figure 4 Final double $\mathrm{J}$ placement. 
Fig 1.

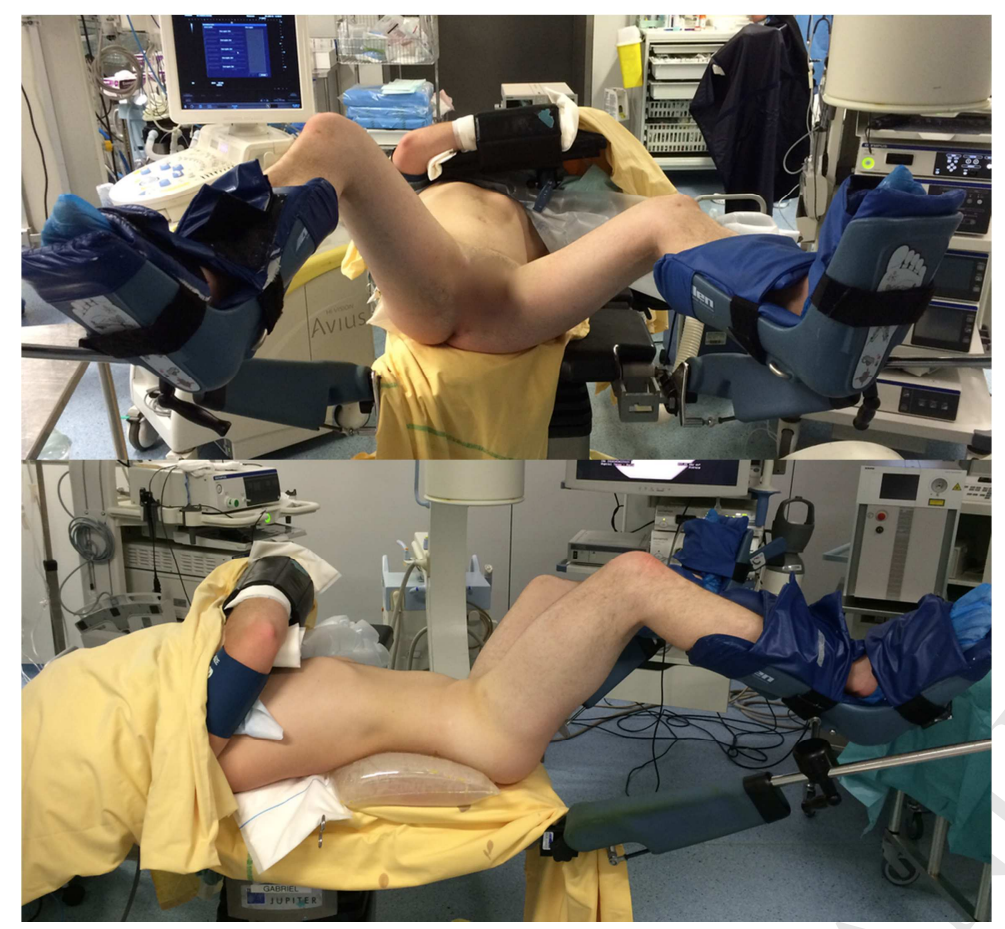

Galdakao-modified supine position for endoscopic combined surgery.

Fig 2.
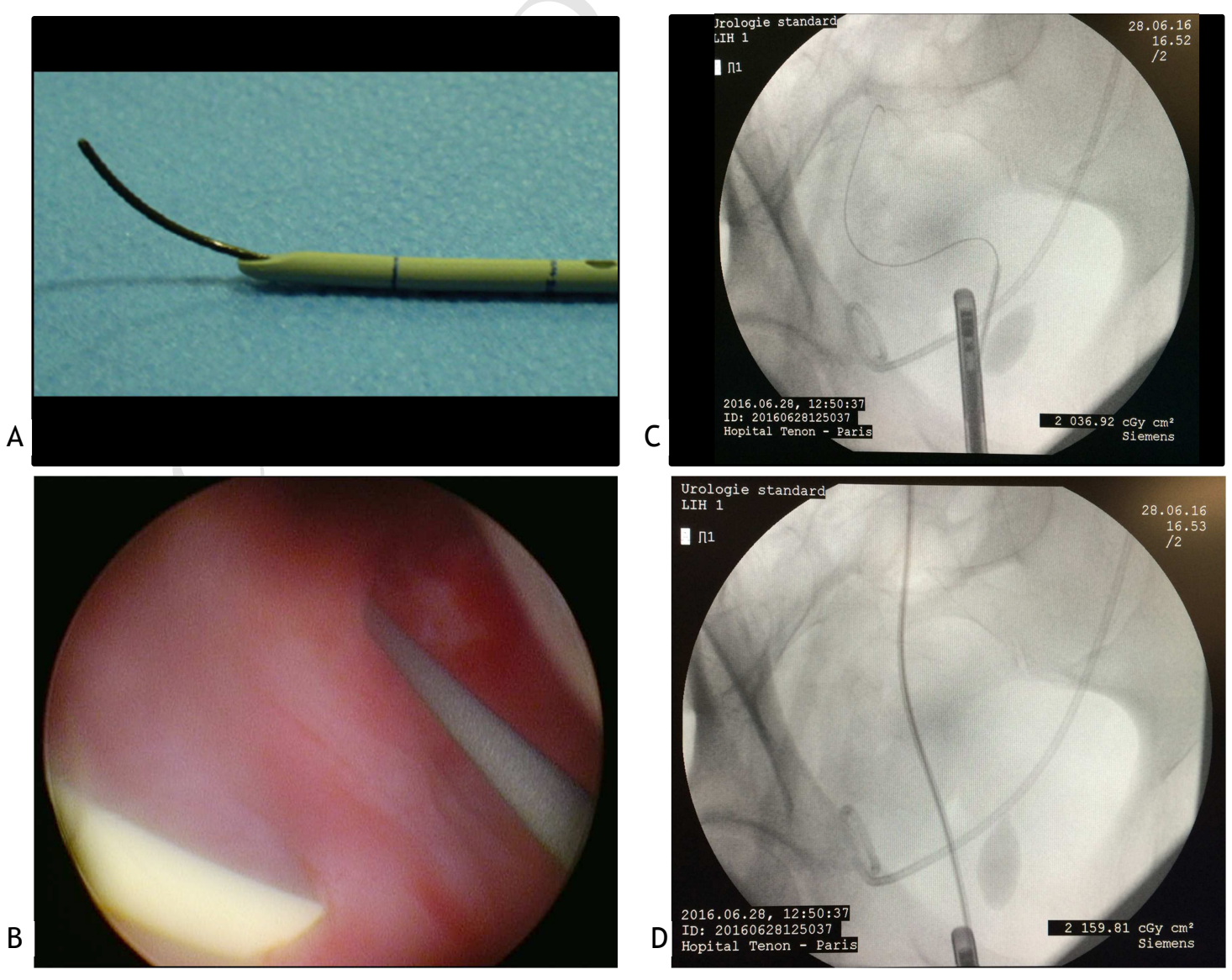
a. 7Fr angled tip catheter (Coloplast, France) and a 0.035 in angled tip hydrophilic Terumo stiff wire (Terumo, Japan).

b. Endoscopic view of the inverted orifice disposition and access (superior orifice right kidney orifice with wire, inferior left kidney orifice with double J) .

c. Cross-trigonal ureteral kinking with wire in place.

d. Ureteral reorientation in a straight axis.

Fig 3.

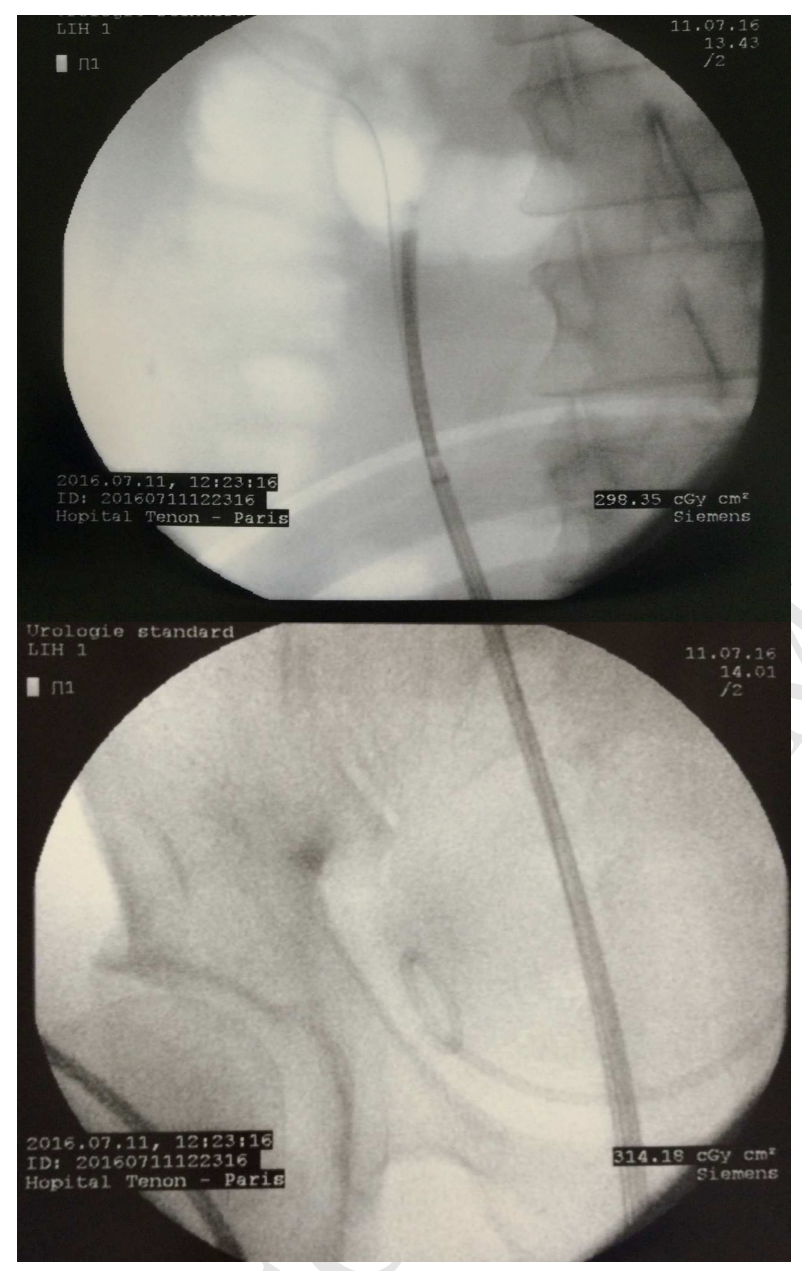

10/12 Re-Trace UAS (Coloplast, France) in place in the straight ureter with a safety guidewire. A disposable ureteroscope was used. 
Fig 4.

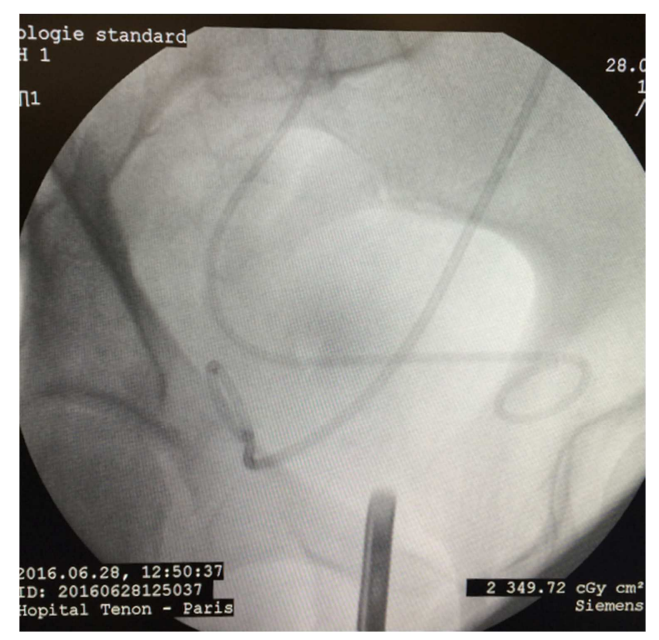

Final double J placement. 
Highlights

- Flexible ureteroscopy (fURS) is a challenging procedure in abnormal ureteral anatomies as in the Cohen Cross-Trigonal ureteroneocystostomy.

- We describe a feasible fURS technique with the latest instruments to and to discuss their advantages.

- A 7Fr angled tip catheter and a 0.035 inch hydrophilic angled tip stiff wire, a 10/12 Ureteral access sheath and a disposable ureteroscope were used.

- The modern fURS technique was found feasible and safe in patients with $\mathrm{Cl}$. No complication s were reported. 